\title{
Effects of Applied Pressure on the Brazing of Superplastic INCONEL 718 Superalloy
}

\begin{abstract}
M.S. YEH and T.H. CHUANG
A superplastic INCONEL 718 superalloy was brazed with a Ni-P and a Ni-Cr-P amorphous filler metal. The effects of applied pressure on the bonding strength, microhardness, and corrosion resistance were studied. The results showed that the brazements with Ni-Cr-P filler metal have higher bonding strength and better corrosion resistance than those with Ni-P filler metal using a conventional brazing method without applied pressure. When brazing was conducted under applied pressure, the bonding strength increased with applied pressure for the brazements with both filler metals. This was caused by a decrease of intermetallic phase through ejection of the liquid phase enriched with melting temperature depressants in the molten filler metals from the joint clearance. Corrosion tests show that these brazements failed at the brazed joint and at the grain boundaries in the region adjacent to the brazement.
\end{abstract}

\section{INTRODUCTION}

THE nickel-base superalloy possesses excellent properties at elevated temperatures and has been widely used in automobile, aerospace, and nuclear industries. However, complex components of nickel-base superalloy can only be obtained with difficulty using conventional mechanical processing. The high-temperature brazing method is an important joining process for manufacturing complex components. There are many filler metals, especially nickel-base filler metals, which have been developed for the brazing of nickel-base superalloys. ${ }^{[1,2]}$ In order to lower the liquidus of nickel-base filler metals, melting temperature depressants such as phosphorus, silicon, boron, and palladium were added. However, intermetallic phases, which are extremely hard and brittle, were formed along the centerline of the joint and decreased the strength of the brazements. Longer brazing time, higher brazing temperature, or narrower joint clearance has been suggested in order to eliminate brittle intermetallic phases.

Applying a moderate compressive load to the brazing method has been reported to compare favorably with the conventional brazing method. Rabinkin and Pounds ${ }^{[3]}$ found that for brazing copper with copper-phosphorus filler metal under an applied pressure of $9.8 \mathrm{MPa}$, its Charpy impact energy was increased and the microstructure of the joint was changed. An ejection model had been proposed to explain the increase in brazement strength. According to this model, the liquid phase enriched with melting temperature depressants was ejected out of the brazing joint, which resulted in the disappearance of brittle intermetallic phases and an increase in ductile phases. A similar beneficial effect from applied pressure in the brazing of a superalloy was also found by Dammer. ${ }^{[4]}$

In this study, the effects of applied pressure on the braz-

M.S. YEH, Associate Professor, is with the Department of Mechanical Engineering, Chung-Hua Polytechnic Institute, Taiwan, 300, Republic of China. T.H. CHUANG, Professor, is with the Institute of Materials Science and Engineering, National Taiwan University, Taiwan, 106, Republic of China.

Manuscript submitted January 2, 1996. ing of a superplastic INCONEL* 718 superalloy with two

*INCONEL is a trademark of INCO Alloys International, Inc., Huntington, WV.

nickel-base filler metals were investigated. For this purpose, the bonding strength, microhardness, and corrosion behavior of the brazements were evaluated after brazing under various pressures.

\section{EXPERIMENTAL PROCEDURE}

The chemical composition of the superplastic INCONEL 718 superalloy (INCONEL 718SPF), manufactured by INCO Alloys International, Inc., which was used in this study, is given in Table I. This alloy possesses a grain size of about $10 \mu \mathrm{m}$ and reaches a total strain of about 194.0 pct with the initial strain rate of $1.3 \times 10^{-3} \mathrm{~s}^{-1}$ at a temperature of $954{ }^{\circ} \mathrm{C} .{ }^{[5]}$ Alloy strips of $34 \times 15 \mathrm{~mm}$ with a thickness of $1.3 \mathrm{~mm}$ were cut from the as-received sheet material. The surfaces to be fayed were prepared by grinding with 150 -grit $\mathrm{SiC}$ paper, rinsing in distilled water, ultrasonic cleaning in $5 \mathrm{~g} / \mathrm{L} \mathrm{NaOH}$ solution, and finally rinsing in acetone. The arithmetical average roughness (Ra) is $0.3 \mu \mathrm{m}$.

Two amorphous foils with compositions of Ni-11 P and Ni-14 Cr-10 P (wt pct), produced by Metglas Products, (Allied Signal Co., Parsippany, NJ) an Allied Signal Co., were used as the filler metals for brazing. The thickness of both filler metals was about $37 \mu \mathrm{m}$. The melting characteristics of the filler metals were determined by differential thermal analysis (Figure 1). Their liquidus and solidus are listed in Table II. As the brazing specimens, two INCONEL 718SPF strips sandwiched with a filler metal foil were arranged with an overlap of $3 T$ ( $T=1.3 \mathrm{~mm}$, sheet thickness). The pressure brazing tests were then carried out at brazing temperature for 10 minutes in a hot vacuum press, under a vacuum of the order of $10^{-4}$ torr with an applied pressure of from 0 to $7.0 \mathrm{MPa}$ (for Ni-11P filler metal) and from 0 to 10.5 $\mathrm{MPa}$ (for Ni-14Cr-10P filler metal). In order to prevent the dissolution of the strengthening phases in the INCONEL $718 \mathrm{SPF}$ superalloy and to make sure the filler metals reached a liquid state, a brazing temperature of $980{ }^{\circ} \mathrm{C}$ was 
Table I. The Chemical Composition of INCONEL 718SPF Superalloy

\begin{tabular}{cccccccc}
\hline $\mathrm{C}$ & $\mathrm{Mn}$ & $\mathrm{Fe}$ & $\mathrm{Si}$ & $\mathrm{Cu}$ & $\mathrm{Ni}$ & $\mathrm{Cr}$ & $\mathrm{Al}$ \\
\hline 0.03 & 0.08 & 17.9 & 0.11 & 0.09 & 53.85 & 18.26 & $\mathrm{Nb}+\mathrm{Ta}$ \\
$\mathrm{Ti}$ & $\mathrm{Co}$ & $\mathrm{Mo}$ & $\mathrm{P}$ & $\mathrm{B}$ & $\mathrm{S}$ & $\mathrm{Na}$ \\
1.06 & 0.15 & 3.01 & 0.011 & 0.002 & 0.001 & 4.92 & \\
\hline
\end{tabular}

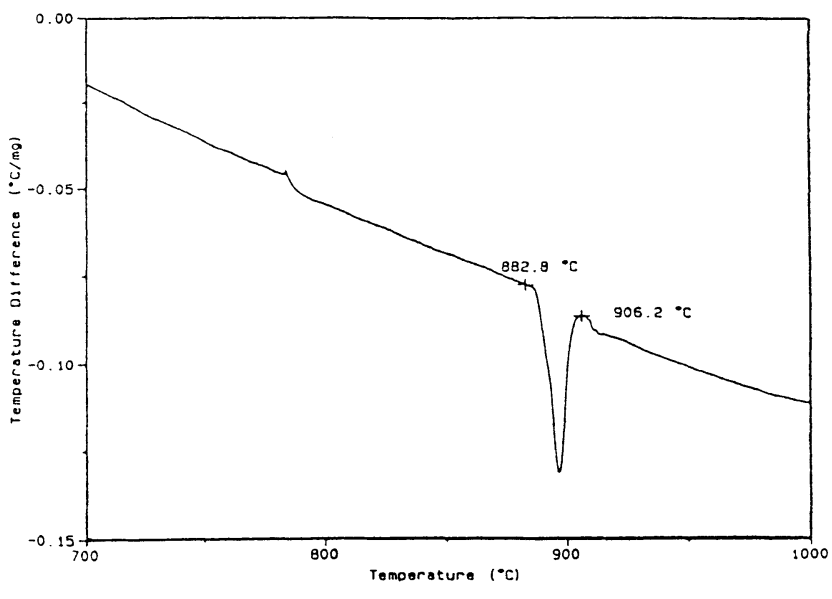

(a)

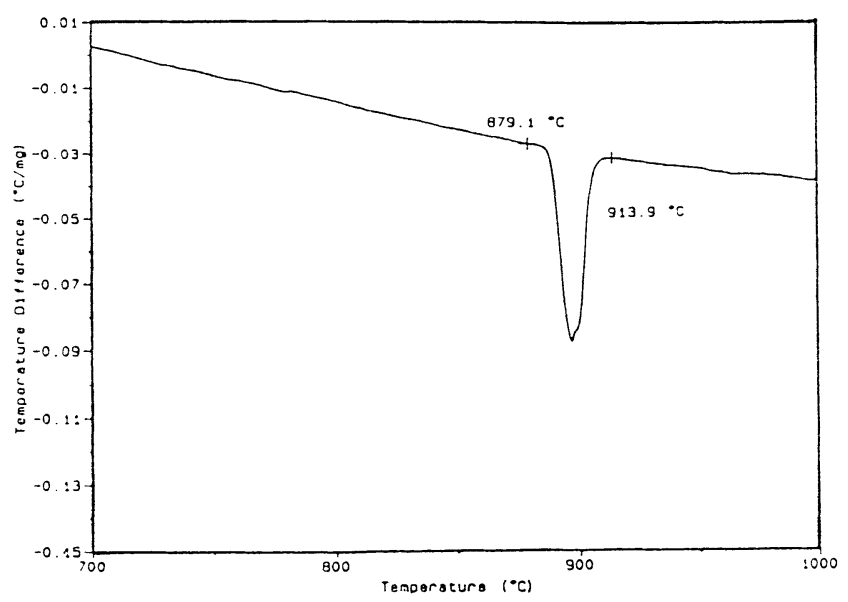

(b)

Fig. 1-Thermograms of various alloys: (a) Ni-P filler metal and (b) Ni-Cr-P filler metal.

Table II. The Solidus, Liquidus, and Brazing Temperatures of Braze Filler Metals

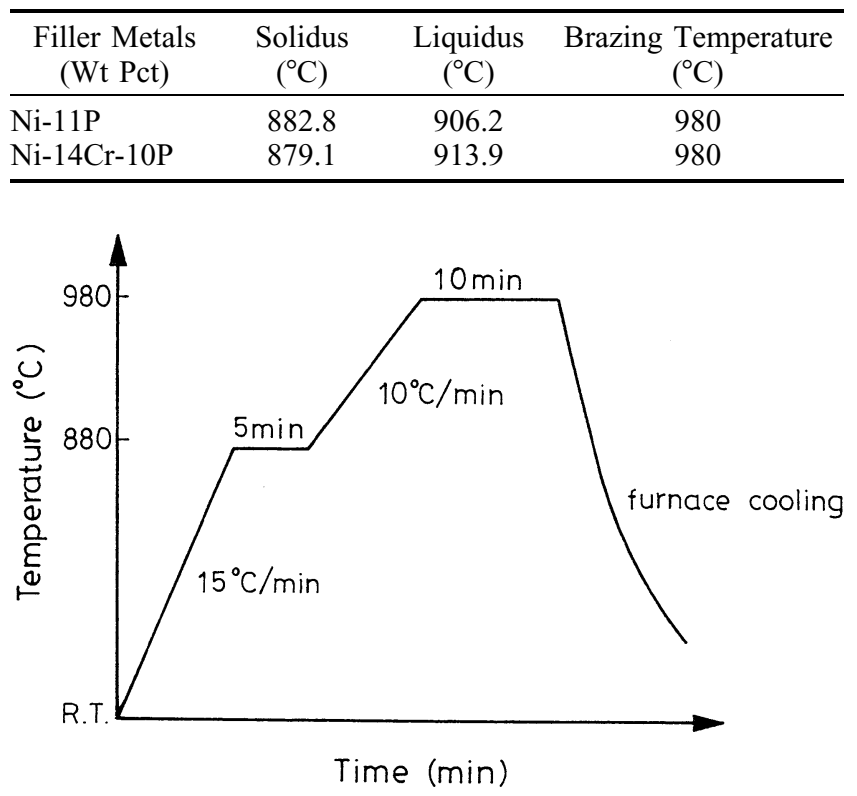

Fig. 2-Typical pressure brazing process.

chosen. A typical pressure brazing process is shown in Figure 2 . The average heating rate was about $10{ }^{\circ} \mathrm{C} / \mathrm{min}$. Also, for the study of wettability and fluidity, $10 \times 10 \mathrm{~mm}$ of filler metal foils were placed on INCONEL 718SPF superalloy plates and heated to $980{ }^{\circ} \mathrm{C}$ for various lengths of time.

After brazing, the brazements were machined to the dimensions shown in Figure 3 with a wire-cut electric discharge machine. Specimens were tensile shear tested with the modifying method proposed by Holko and Moore ${ }^{[6]}$ in air at room temperature at a crosshead speed of 0.5
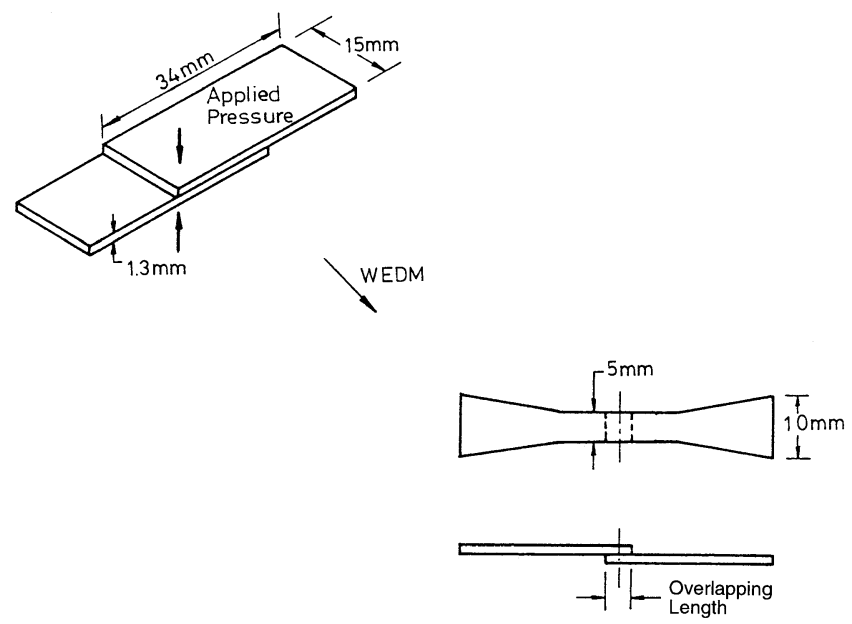

Fig. 3-The dimensions for single lap shear test specimen.

\section{A: molten filler metal \\ B: precursor ring}

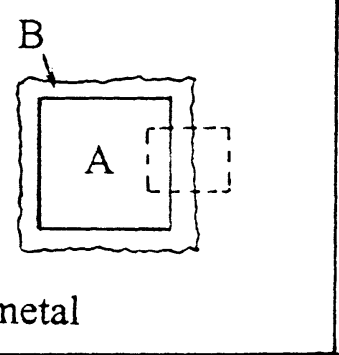

Fig. 4-Schematic of wetting test specimens. 

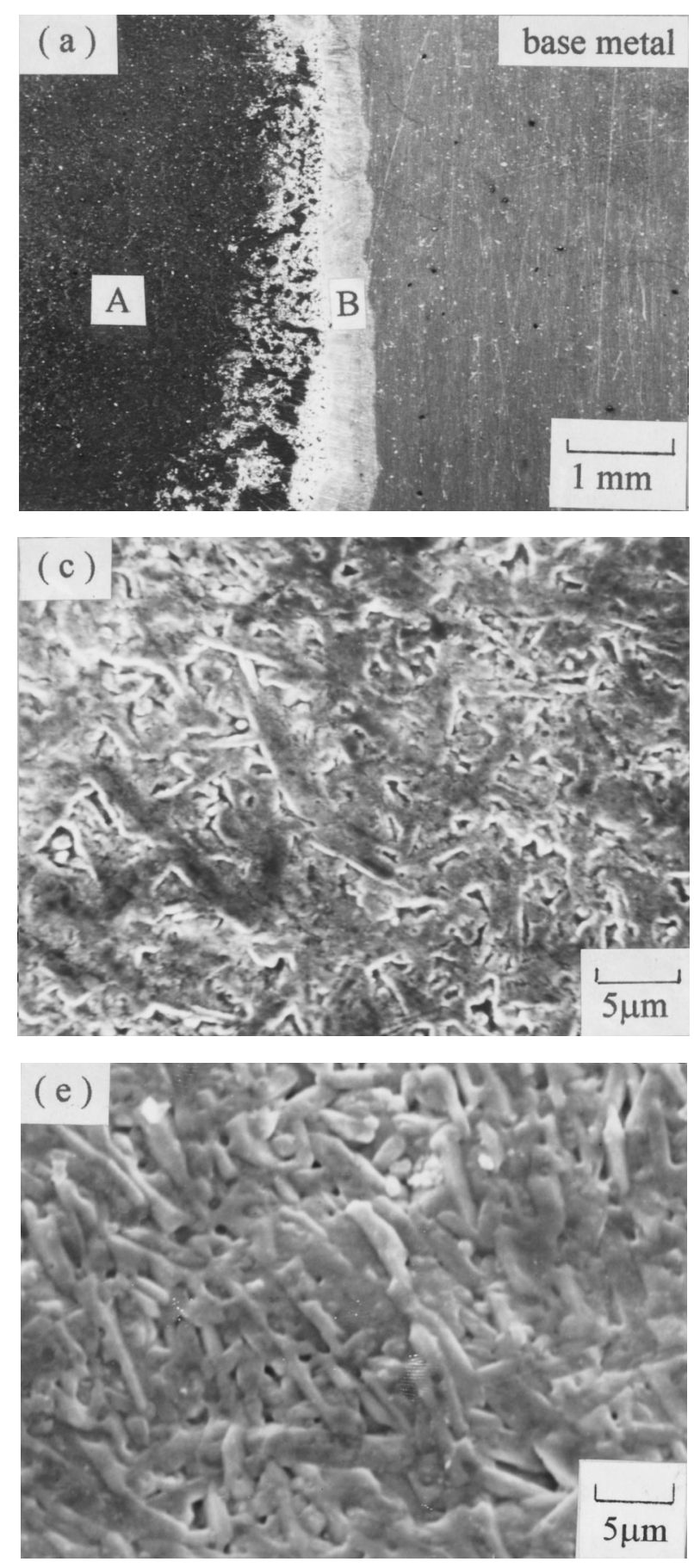
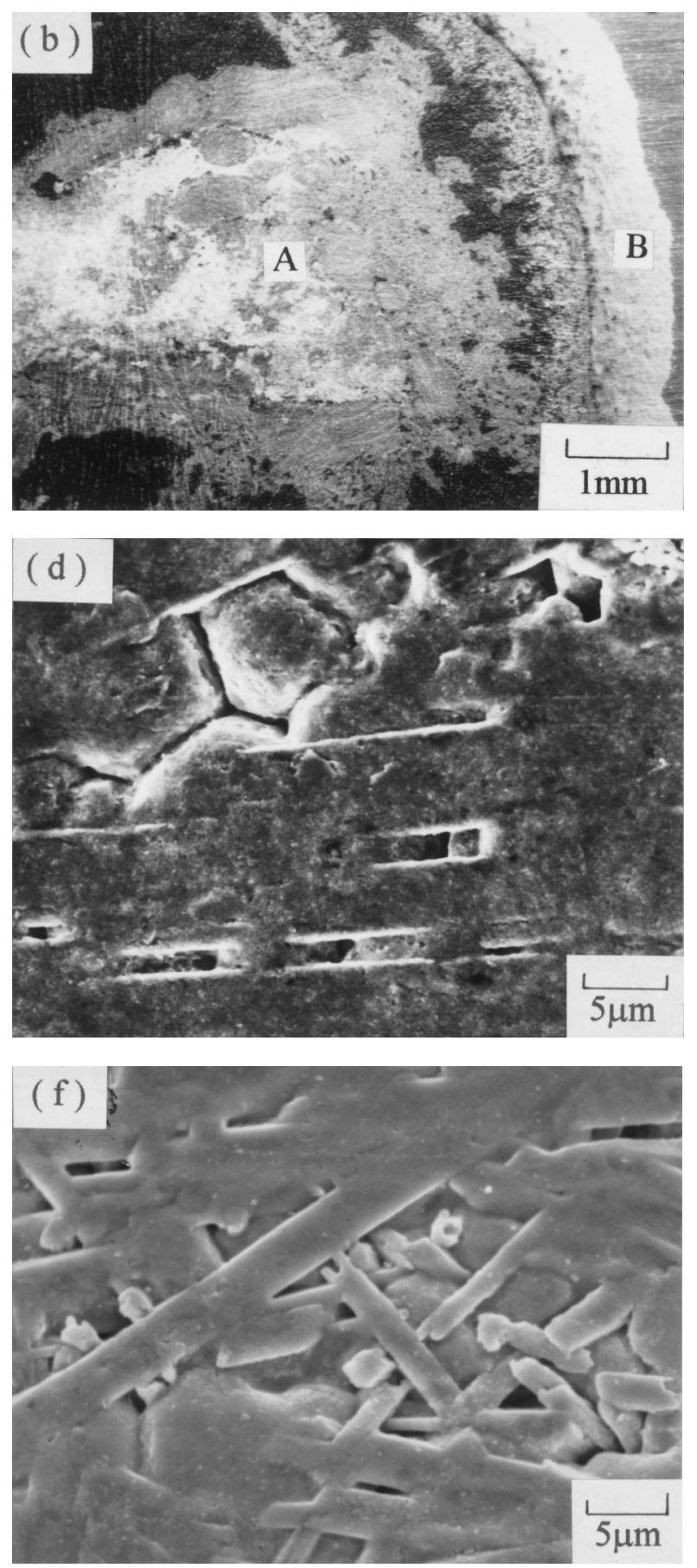

Fig. 5-The spreadability of Ni-P filler metal on INCONEL 718SPF superalloy in a vacuum of $10^{-4}$ torr at $980{ }^{\circ} \mathrm{C}$ for various lengths of time: $(a)$ top view for $10 \mathrm{~min},(b)$ top view for $30 \mathrm{~min},(c)$ microstructure of molten filler metal for $10 \mathrm{~min},(d)$ microstructure of precursor ring for 10 min, $(e)$ microstructure of molten filler metal for $30 \mathrm{~min}$, and $(f)$ microstructure of precursor ring for $30 \mathrm{~min}$.

$\mathrm{mm} / \mathrm{min}$. The shear strength $(\tau)$ was calculated by the equation

$$
\tau=\frac{P}{A W}
$$

where $P$ is the breaking load, $A$ is the overlap length, $T$ is the sheet thickness, and $W$ is the sample width.

Furthermore, the microhardness was measured along the centerline of the joint at the filler metal, and the phase chemical compositions were analyzed by energy dispersive
X-ray spectroscopy (EDX) in a scanning electron microscope. The corrosion properties of brazements with both filler metals were examined at room temperature in a 3.5 pct $\mathrm{NaCl}$ solution. Corrosion specimens were cut from the brazement orthogonal to the bonding interface and ground with 600-grit $\mathrm{SiC}$ paper and then cleaned in acetone. The corrosion potential $\left(\Phi_{\text {corr }}\right)$ was measured with respect to the saturated calomel electrode (SCE), and the potentiostatic polarization tests were carried out from -600 $\mathrm{mV}\left(v s \Phi_{\text {corr }}\right)$ to $+1.2 \mathrm{~V}_{\mathrm{SCE}}$ with a scanning rate of $1 \mathrm{mV} / \mathrm{s}$. 

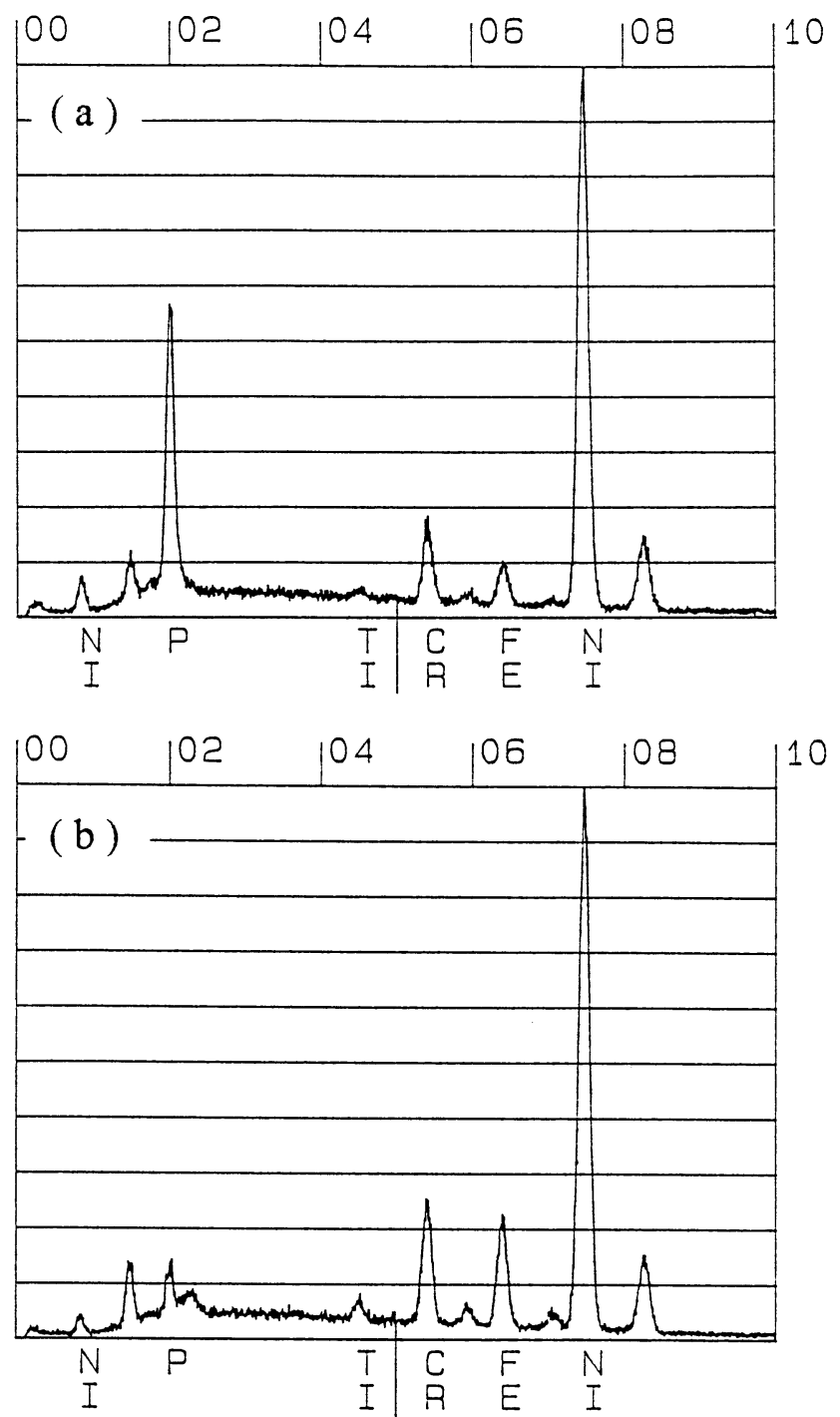

Fig. 6-The EDX spectra of Ni-P filler metal on INCONEL 718SPF superalloy in a vacuum of $10^{-4}$ torr at $980{ }^{\circ} \mathrm{C}$ for $10 \mathrm{~min}$. (a) $\mathrm{EDX}$ spectrum for dendritic structure and (b) EDX spectrum for grainy structure.

\section{RESULTS AND DISCUSSION}

\section{A. Wetting Behavior}

An annular precursor ring was observed around the molten filler metal for all the filler metals placed on INCONEL $718 \mathrm{SPF}$ superalloy plates heated to $980{ }^{\circ} \mathrm{C}$ for various lengths of time (Figure 4). The Ni-P filler metal on INCONEL 718SPF had good wettability at $980{ }^{\circ} \mathrm{C}$ for 10 and 30 minutes and a partial area was shown by scanning electron microscope (SEM) (Figures 5(a) and (b), respectively). The range of the molten filler metal spreading area (region A) increased with the brazing time but was not observed in the range of the precursor ring (region B). The latter possessed a dense and dendritic structure (Figure 5(c)); however, the former consisted of eutectic colonies and a grainy structure (Figure $5(\mathrm{~d})$ ). The samples brazed at $980{ }^{\circ} \mathrm{C}$ for 30 and 10 minutes had similar microstructures and phase compositions in the precursor ring (Figures 5(e) and (f)). The EDX spectra showed the compositions of dendritic structure (Figure 6(a)) and grainy structure (Figure 6(b)).
For Ni-Cr-P filler metal, the range of the precursor ring increased about from 400 to $700 \mu \mathrm{m}$ with an increase in the brazing time from 10 to 30 minutes (Figure 7(a) and 7(b)). At the same time, the range of molten filler metal spreading area also increased. The main structure of the molten filler metal (region A) was a grainy structure (Figures 7(c) and (e)), and the main structure of the precursor ring (region B) was a dendritic structure (Figures 7(d) and (f)). The composition of the dendritic structure was that of a chromium phosphide compound (Figure 8(a)). However, the grainy structure was a nickel solid solution (Figure 8(b)).

According to the Ni-P phase diagram, ${ }^{[7]}$ there exists a eutectic reaction of the nickel solid solution and the $\mathrm{Ni}_{3} \mathrm{P}$ intermetallic phase at $880{ }^{\circ} \mathrm{C}$ with a composition of $\mathrm{Ni}-11$ wt pct P. During the melting of the filler metals, phosphorus diffused into the base metal through lattice and grain boundaries. The precipitations of phosphide were formed in the grain interiors and at the grain boundaries of the base metal near the brazed joint.

\section{B. Microstructure of Brazed Joints}

Figure 9 shows the microstructure of the brazement edge for an INCONEL 718SPF superalloy brazed with both filler metals under an applied pressure of 7.0 MPa. Since a liquid phase is unable to support shear force, the liquid metal was ejected out of the joint and the joint clearance width changed at the same time. Three zones were found in sequence from the joint outward - the filler metal, an interfacial diffusion zone, and the base metal. A series of microstructures for joints brazed with Ni-P and Ni-Cr-P filler metals under various external loads are shown in Figures 10 and 11, respectively. There are two major phases shown in all tested brazements: (a) nickel solid solution and (b) intermetallic phases. The Ni-P phase diagram showed that phosphorus had very small solubility in the nickel solid solution and formed intermetallic phases, i.e., $\mathrm{Ni}_{3} \mathrm{P}, \mathrm{Ni}_{5} \mathrm{P}_{2}$, and $\mathrm{Ni}_{12} \mathrm{P}_{5}$. In this study, the individual phase compositions of Figures 10 and 11 are summarized in Tables III and IV, respectively.

Furthermore, the brazed joint clearance width of the brazements made with Ni-P filler metal decreased with an increase in applied external load. The volume of intermetallic phases was decreased and joint clearance was primarily occupied by the nickel solid solution. However, the brittle intermetallic phases of brazements with Ni-Cr-P filler metal still aggregated along the centerline of the joint. When brazing under pressure higher than $7.0 \mathrm{MPa}$, the brittle intermetallic phases were embedded in the ductile nickel solid solution (Figure 11(d)). This observation means that a higher pressure is required for changing the microstructures of brazements with Ni-Cr-P filler metal.

In the brazing process, phosphorus diffused into the base metal and an isothermal solidification of the nickel solid solution occurred in the joint. If the specimen cooled before isothermal solidification, intermetallic phases were formed along the centerline of the joint. When pressure was applied to the brazements, a liquid phase enriched with a low-melting depressant component, such as phosphorus, was ejected from the joint, and the joint clearance became narrower. Simultaneously, the phosphorus concentration decreased in the remaining liquid phase in the joint. Based on the Ni-P 

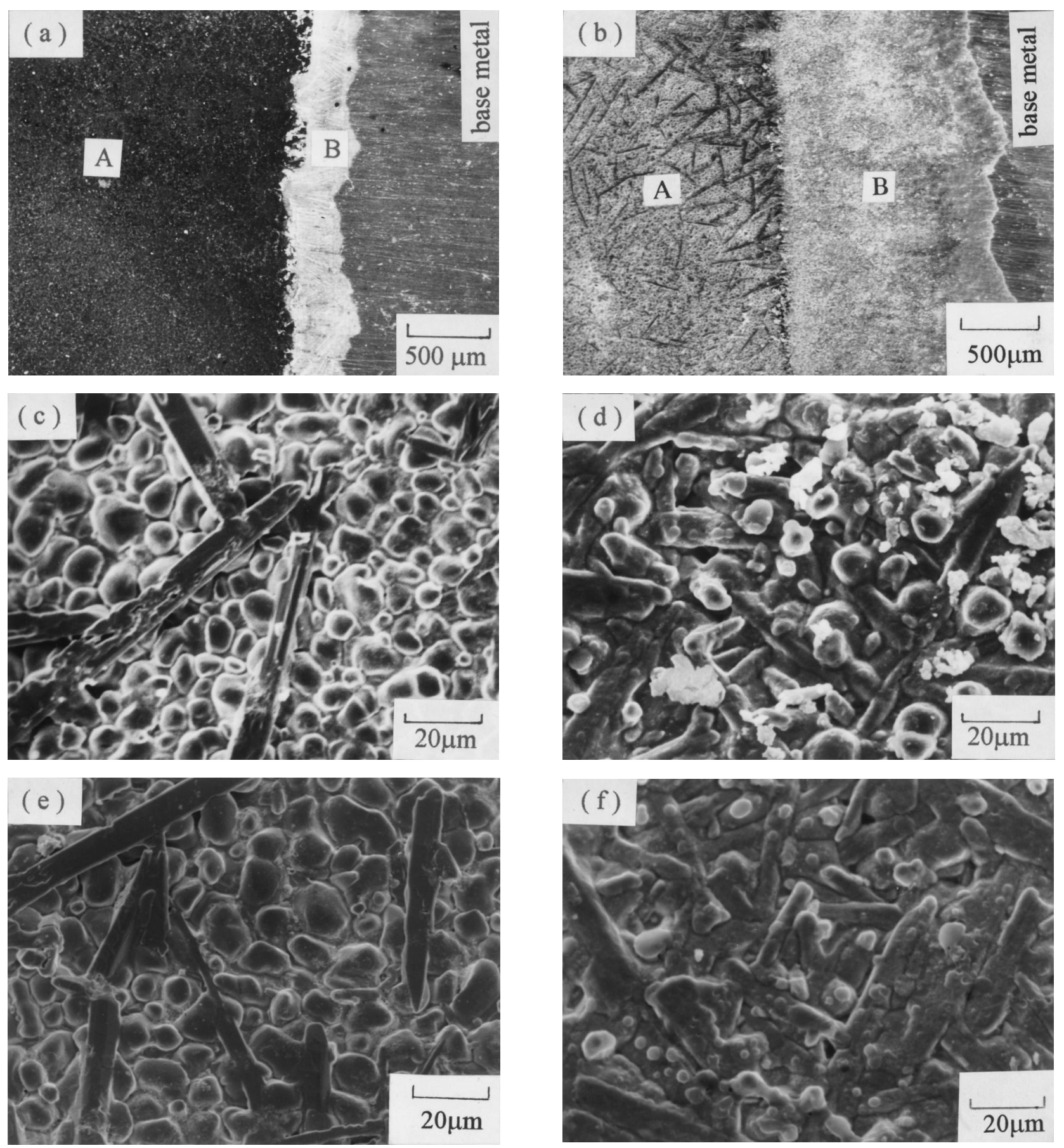

Fig. 7-The spreadability of Ni-Cr-P on INCONEL 718SPF superalloy in a vacuum of $10^{-4}$ torr at $980{ }^{\circ} \mathrm{C}$ for various lengths of time: $(a)$ top view for $10 \mathrm{~min},(b)$ top view for $30 \mathrm{~min},(c)$ microstructure of molten filler metal for $10 \mathrm{~min},(d)$ microstructure of precursor ring for 10 min, $(e)$ microstructure of molten filler metal for $30 \mathrm{~min}$, and $(f)$ microstructure of precursor ring for $30 \mathrm{~min}$.

phase diagram, the volume fraction of brittle intermetallic phases was decreased using the lever rule. For a Ni-Cr-P filler metal, chromium influenced the diffusivity of phosphorus in the filler metal and increased the strength of the nickel solid solution. The pressure for ejection of the liquid exceeded 7.0 $\mathrm{MPa}$, and dramatic changes in microstructure were observed.

\section{Mechanical Properties}

The results of the mechanical properties of the brazements with Ni-P and Ni-Cr-P filler metals are shown in
Figures 12 and 13, respectively. Average shear strength is determined with three brazed samples. The shear strength of Ni-P brazements without applied pressure was $95.5 \mathrm{MPa}$. During the pressure brazing process, shear strength increased with an applied external load. The highest shear strength was $227.3 \mathrm{MPa}$ after brazing under an external pressure of 7.0 MPa. Under the same brazing conditions, the shear strength of the brazements with Ni-Cr-P filler metal had similar tendencies to the brazements with Ni-P filler metal. For brazing without applied pressure, the brazement with Ni-Cr-P filler metal possessed a higher bonding 


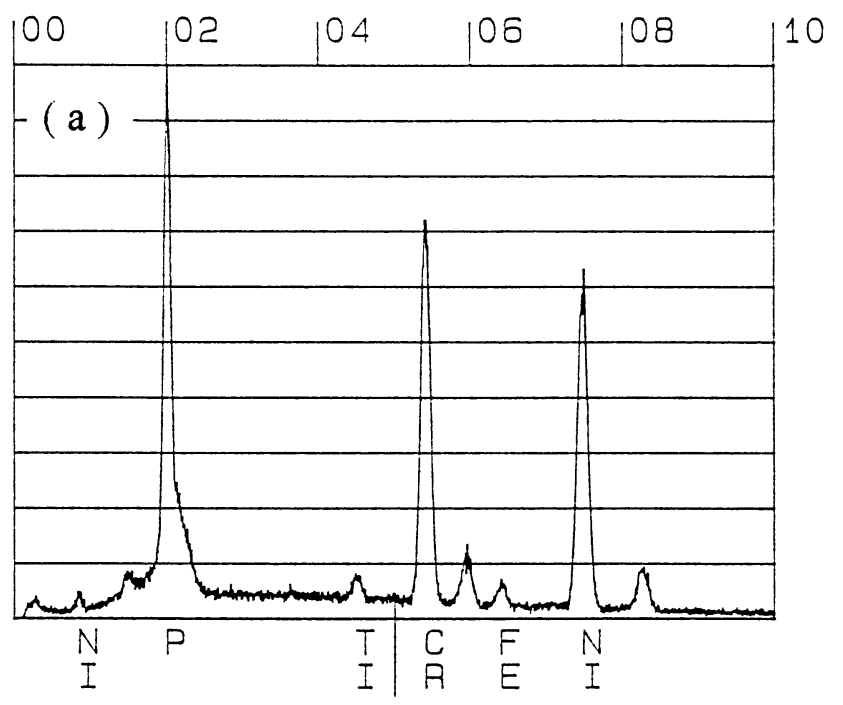

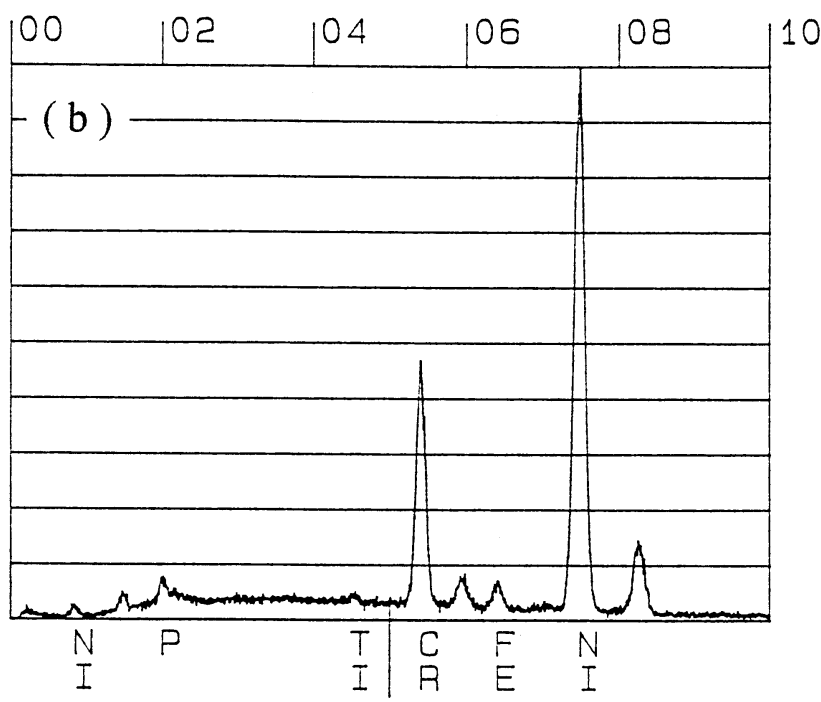

Fig. 8-The EDX spectra of Ni-Cr-P filler metal on INCONEL 718SPF superalloy in a vacuum of $10^{-4}$ torr at $980{ }^{\circ} \mathrm{C}$ for $10 \mathrm{~min}$ : (a) EDX spectrum for dendritic structure and (b) EDX spectrum for grainy structure.

strength than the one with Ni-P filler metal. The result can be attributed to the solid solution strengthening effect of the Ni-Cr-P filler metal with a chromium content.

Microhardness measured along the centerline of the joint at the filler metal is based on an average taken from 10 tests on one sample. The intermetallic phases have higher microhardness than the nickel solid solution. A large scattering microhardness was observed in this case, as the hard intermetallic phases were embedded in the ductile nickel solid solution. The average microhardness of Ni-P brazements at the joint centerline decreased with the applied load as a result of reducing the volume of intermetallic phases. For Ni-Cr-P brazements, the average microhardness of the filler metal decreased under pressures exceeding 7.0 MPa.

All the brazements failed at the bonding interface in tensile shear tests. Figure 14 shows the fracture surface of the brazements with Ni-P filler metal under various pressures. It is seen that the brazements without applied pressure failed along the brazed interface (Figure 14(a)), while a tear dimple fractography became obvious with the increase in
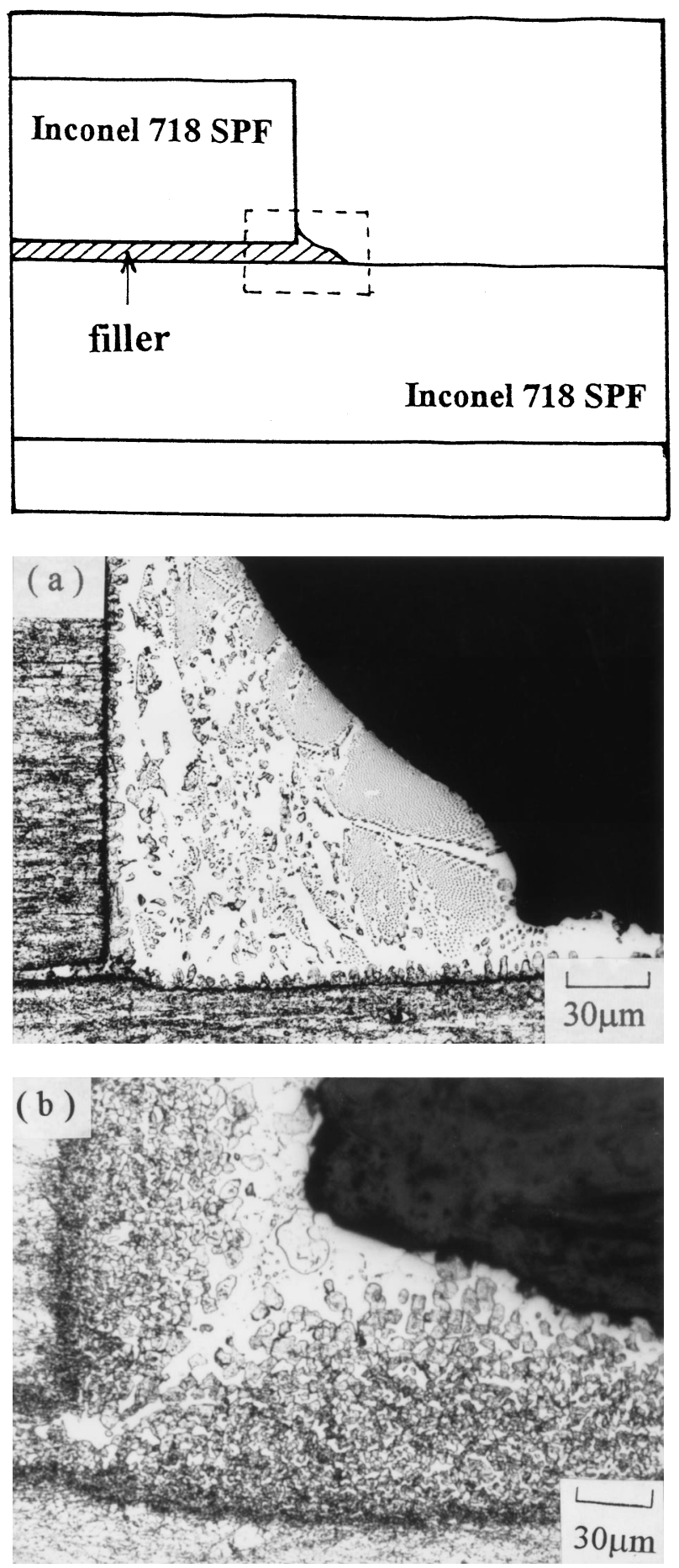

Fig. 9-Microstructure of brazement edge after brazing with two filler metals at $980{ }^{\circ} \mathrm{C}$ for 10 min under 7.0 MPa: $(a)$ Ni-P filler metal and $(b)$ Ni-Cr-P filler metal.

applied pressure (Figures 14(b) and (c)). A brittle fracture surface was observed in most of the Ni-Cr-P brazements without applied pressure (Figure 15(a)). When brazing is conducted under applied pressure, the fracture path occurs along the nickel solid solution/intermetallic phase interface (Figure 15(b)).

In the brazing process, the strength of brazements with an intermetallic phase joint is always lower than the strength of brazements with an intermetallic-free joint. As 

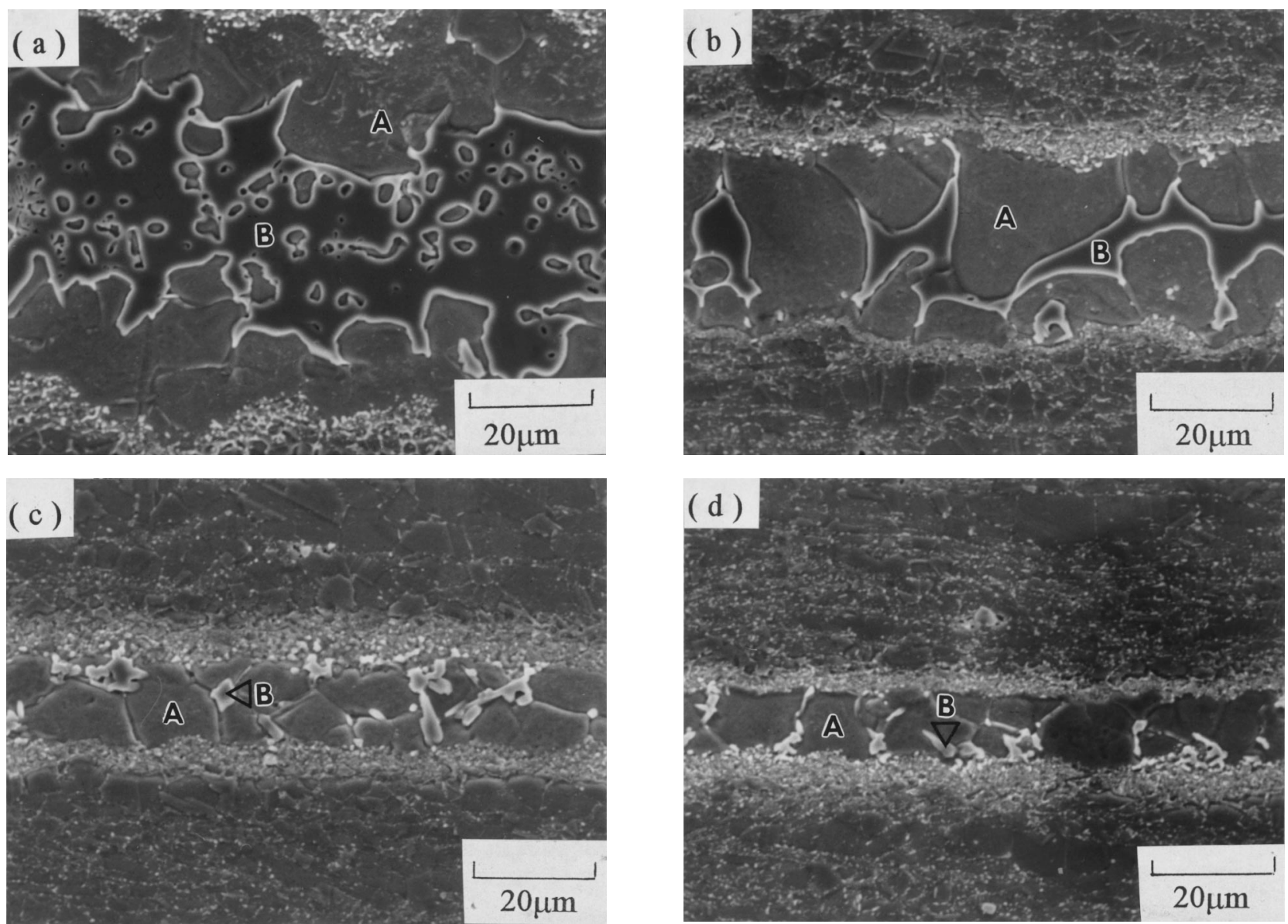

Fig. 10-Microstructure of brazement with Ni-P filler metal under applied external pressure after brazing at $980{ }^{\circ} \mathrm{C}$ for $10 \mathrm{~min}:(a) 0 \mathrm{MPa},(b) 2.45 \mathrm{MPa}$, (c) $4.9 \mathrm{MPa}$, and $(d) 7.0 \mathrm{MPa}$

mentioned previously, phosphorus diffused into the base metal and the molten filler metal was ejected from the joint, which was enriched with phosphorus. The formation of intermetallic phases in the joint was thus decreased, which resulted in a decrease of microhardness at the centerline of the joint and an increase in bonding strength. Another reason for the increase in the strength of brazements may be a result of the joint clearance becoming narrow. For a very thin filler metal in a joint, the filler metal will deform differently from when it is in thick form. ${ }^{[8,9]}$ When the stress was applied to a joint with a small gap, the filler metal was elasticly constrained by the INCONEL 718 SPF components from deforming, and the strength of the joint increased.

\section{Corrosion Behavior}

The corrosion properties of the base metal and brazements without applied pressure were examined at room temperature in a 3.5 pct $\mathrm{NaCl}$ solution. The polarization curves are shown in Figure 16, and the corrosion properties are summarized in Table V. For an INCONEL 718SPF alloy after brazing at $980{ }^{\circ} \mathrm{C}$ for 10 minutes, the corrosion potential of the brazement base metal was about -154 $\mathrm{mV}_{\mathrm{SCE}}$ and the breakdown potential was about $967 \mathrm{mV}_{\mathrm{SCE}}$. In another case, the brazements with Ni-P and Ni-Cr-P filler metals possessed breakdown potentials of 409 and 552 $\mathrm{mV}_{\mathrm{SCE}}$, respectively, which are more active than that of the base metal. The brazements with Ni-Cr-P filler metal have better corrosion resistance than the brazements with Ni-P filler metal, which can be attributed to the chromium content in the Ni-Cr-P filler metal.

The SEM observations show that corrosion commonly occurred in the brazement and at the grain boundaries of the region adjacent to the brazement. The intercrystalline corrosion tendency in the region adjacent to the brazement was caused by the formation of phosphides at the grain boundaries. After corrosion, the brazements with Ni-P filler metal exhibited dendritic structures in the brazements (Figure 17). However, the joint clearance of the Ni-Cr-P brazements retained a chromium phosphide compound (Figure 18). It is evident from these experiments that the nickel solid solution was easily corroded. The more active breakdown potential of brazements with $\mathrm{Ni}-\mathrm{Cr}-\mathrm{P}$ was caused by the pitting of the nickel solid solution matrix at its joint clearance.

\section{CONCLUSIONS}

The following conclusions were drawn from the present studies.

1. Ni-P and Ni-Cr-P filler metals in the superplastic INCONEL 718 superalloy show good wettability. The wetting area and the precursor ring have different microstructures. Furthermore, phosphide precipitations were formed both in the grains and at grain boundaries 

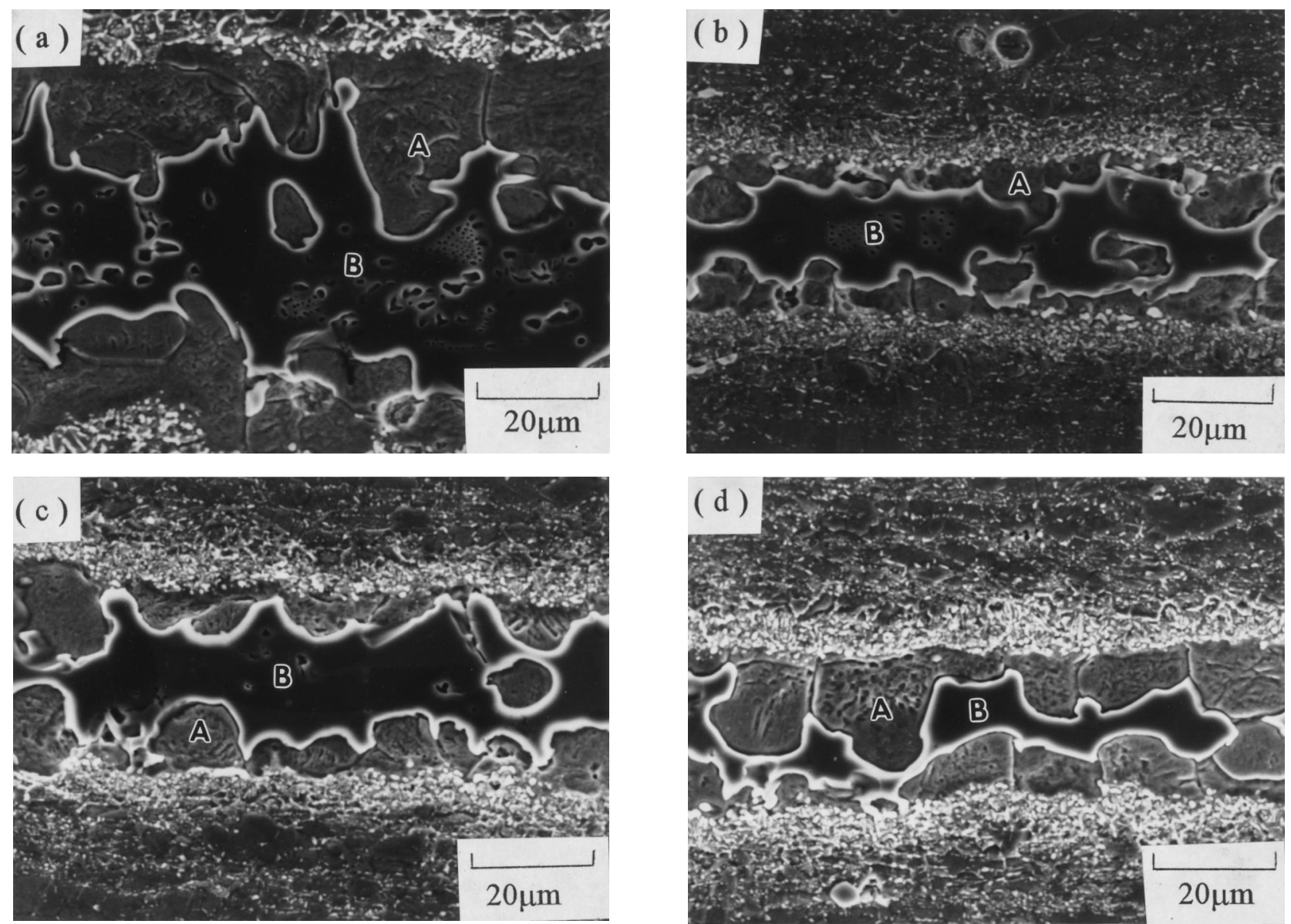

Fig. 11-Microstructure of brazement with Ni-Cr-P filler metal under applied external pressure after brazing at $980{ }^{\circ} \mathrm{C}$ for $10 \mathrm{~min}$ : $(a) 0 \mathrm{MPa}$, $(b) 2.45$ $\mathrm{MPa},(c) 4.9 \mathrm{MPa}$, and (d) 7.0 MPa.

Table III. Phase Compositions Observed in Joints Brazed with Ni-P Filler Metal (Weight Percent)

\begin{tabular}{lll}
\hline & \multicolumn{1}{c}{ Nickel Solid Solution (A) } & \multicolumn{1}{c}{ Intermetallic Phases (B) } \\
\hline Fig. 10(a) & Ni-9.5Cr-12.4Fe-1.5Mo-1.2Nb & Ni-5.3Cr-3.0Fe-1.0Mo-1.0Nb-14.1P \\
Fig. 10(b) & Ni-9.0Cr-12.0Fe-1.7Mo-1.3Nb & Ni-4.8Cr-3.0Fe-0.5Mo-1.0Nb-14.2P \\
Fig. 10(c) & Ni-9.0Cr-11.8Fe-1.6Mo-1.5Nb & Ni-16.6Cr-4.2Fe-2.2Ti-5.4Mo-13.4Nb-16.9P \\
Fig. 10(d) & Ni-7.9Cr-10.5Fe-1.8Mo-1.3Nb & Ni-15.7Cr-4.3Fe-2.3Ti-5.0Mo-13.8Nb-15.7P \\
\hline
\end{tabular}

Table IV. Phase Compositions Observed in Joints Brazed with Ni-Cr-P Filler Metal (Weight Percent)

\begin{tabular}{lll}
\hline & \multicolumn{1}{c}{ Nickel Solid Solution (A) } & \multicolumn{1}{c}{ Intermetallic Phases (B) } \\
\hline Fig. 11(a) & Ni-17.0Cr-8.3Fe-1.4Mo-0.5Nb & Ni-16.7Cr-1.7Fe-0.6Mo-2.4Nb-16.6P \\
Fig. 11(b) & Ni-17.2Cr-3.4Fe-1.5Mo-1.0Nb & Ni-24.5Cr-1.4Fe-1.4Mo-1.2Nb-22.4P \\
Fig. 11(c) & Ni-16.8Cr-5.3Fe-1.7Mo-1.8Nb & Ni-25.0Cr-5.1Fe-0.6Ti-1.8Mo-4.2Nb-19.7P \\
Fig. 11(d) & Ni-16.1Cr-6.2Fe-1.8Mo-1.4Nb & Ni-26.0Cr-5.3Fe-0.9Ti-1.6Mo-5.2Nb-19.4P \\
\hline
\end{tabular}

of the base metal due to the diffusion of phosphorus from filler metals into the base metal.

2. In conventional brazing methods without applied pressure, the brazements with Ni-Cr-P have higher tensile strength and better corrosion resistance than the brazements with Ni-P, which can be attributed to the chromium content of the Ni-Cr-P filler metal.

3. Tensile and shear strength for brazements with the Ni$P$ filler metal increased with applied pressure. Brazements with Ni-Cr-P had a similar tendency when pressures higher than $2.45 \mathrm{MPa}$ were applied.
4. The liquid phase enriched with melting temperature depressants in the molten Ni-P and Ni-Cr-P filler metals was ejected from the joint clearance under applied pressure, which resulted in a decrease of intermetallic phases.

5. In a corrosive environment, the Ni-P and Ni-Cr-P brazements failed at the brazed joint and at the grain boundaries in the region adjacent to the brazement, as a result of phosphide precipitates forming at the grain boundaries and preferential corrosion of the nickel solid solution. 


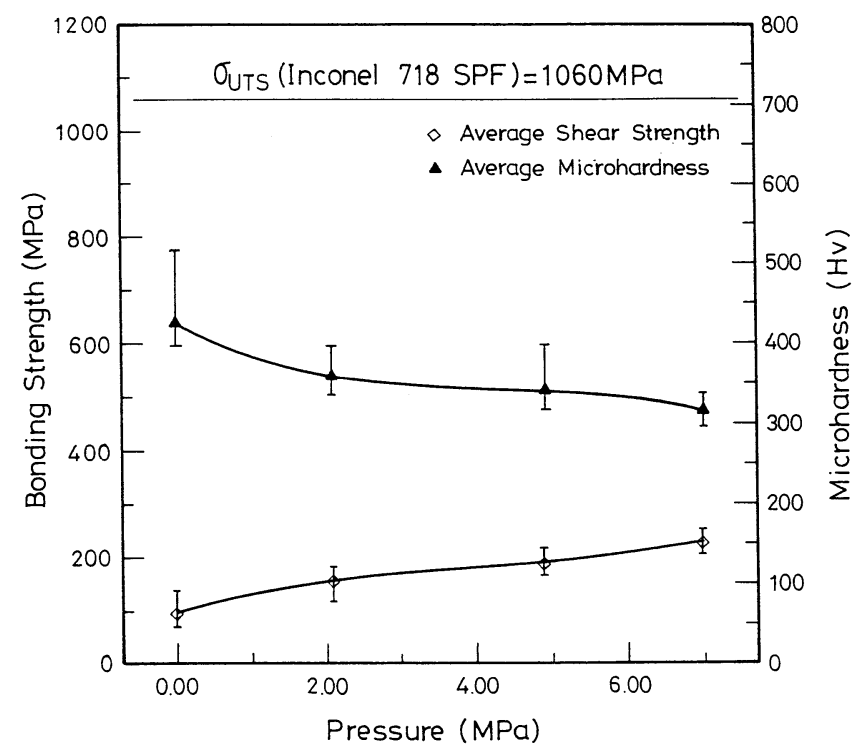

Fig. 12-Bonding strength and microhardness (Hv) of INCONEL 718SPF superalloy brazements with Ni-P filler metal at the centerline of the joint under various pressures.

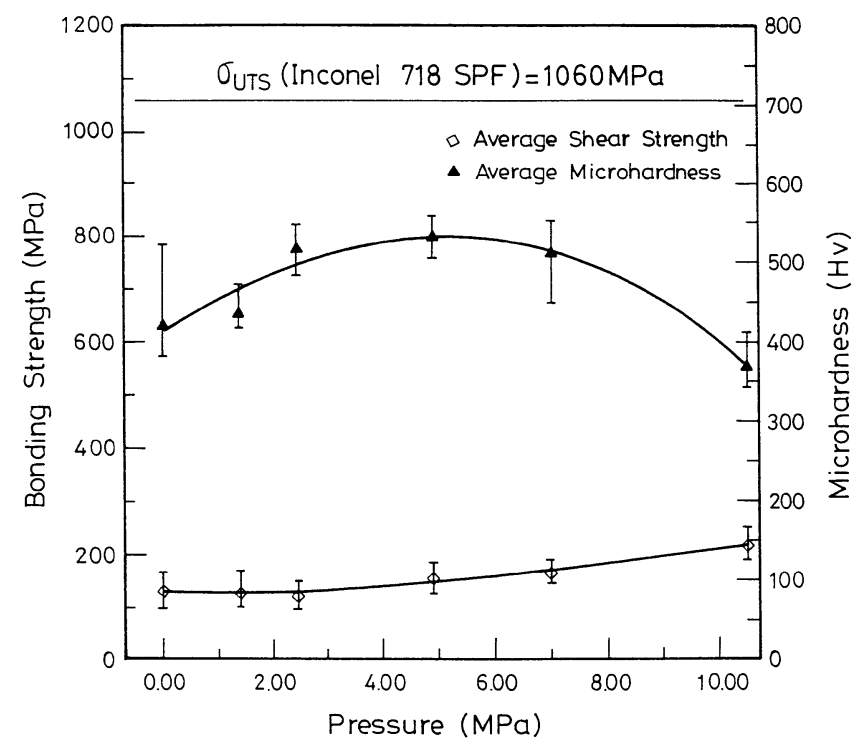

Fig. 13-Bonding strength and microhardness (Hv) of INCONEL 718SPF superalloy brazements with $\mathrm{Ni}-\mathrm{Cr}$-P filler metal at the centerline of the joint under various pressures.

Table V. Corrosion Data for INCONEL 718SPF Superalloy after Brazing

\begin{tabular}{lccc}
\hline & $\begin{array}{c}\Phi_{\text {corr }} \\
(\mathrm{mV})\end{array}$ & $\begin{array}{c}\Phi_{b} \\
(\mathrm{mV})\end{array}$ & $\begin{array}{c}j_{\text {corr }} \\
\left(\mathrm{nA} / \mathrm{cm}^{2}\right)\end{array}$ \\
\hline As-received & -150 & 998 & 18.1 \\
Base metal & -154 & 967 & 19.8 \\
Ni-P brazement & -165 & 409 & 29.6 \\
Ni-Cr-P brazement & -160 & 552 & 20.6 \\
\hline
\end{tabular}

*After brazing at $980{ }^{\circ} \mathrm{C}$ for $10 \mathrm{~min}$

$\Phi_{\text {corr }}$ : corrosion potential; $\Phi_{b}$ : breakdown potential; and $j_{\text {corr }}$ : corrosion current density.
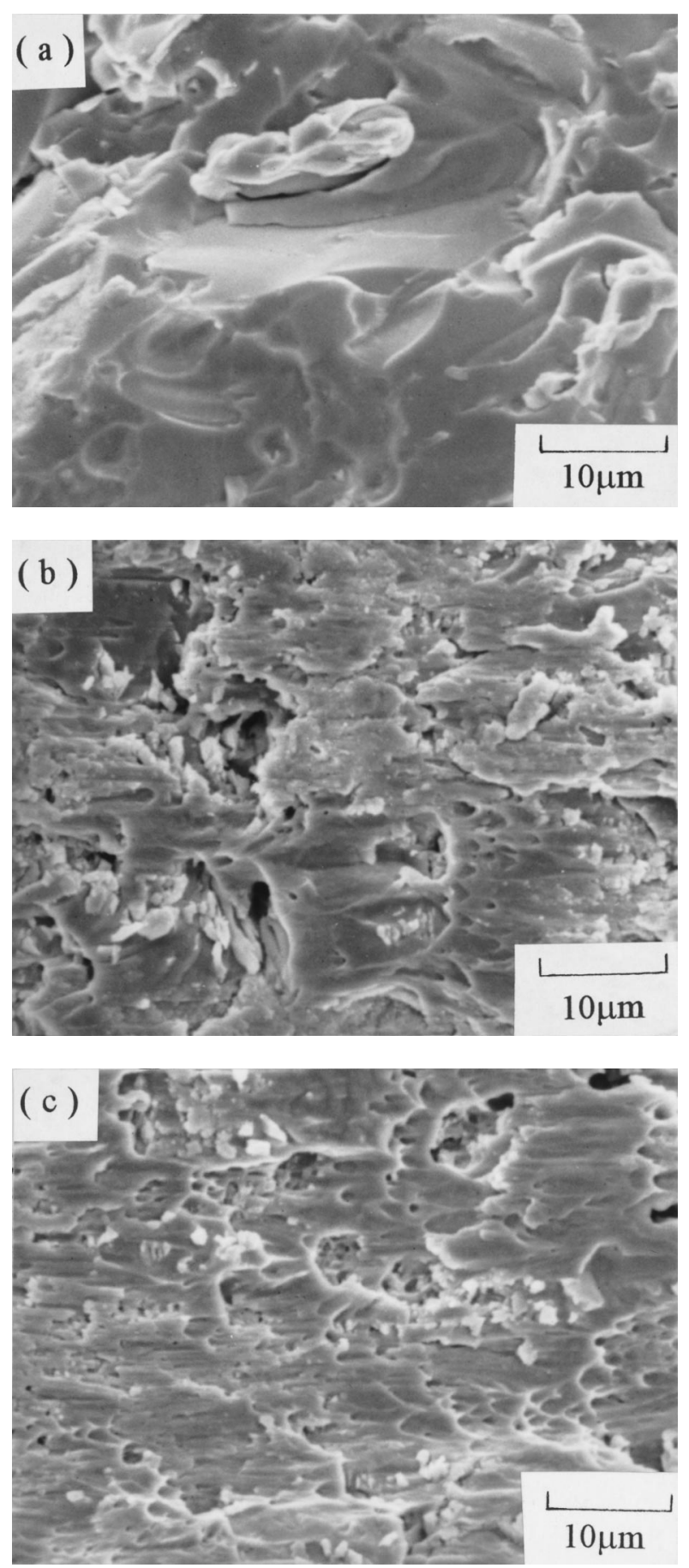

Fig. 14-Fractographs of brazements with Ni-P filler metal after brazing at $980{ }^{\circ} \mathrm{C}$ for $10 \mathrm{~min}$ under various pressures (overlapping length $3 T$ ): $(a)$ $0 \mathrm{MPa},(b) 2.45 \mathrm{MPa}$, and (c) 7.0 $\mathrm{MPa}$. 

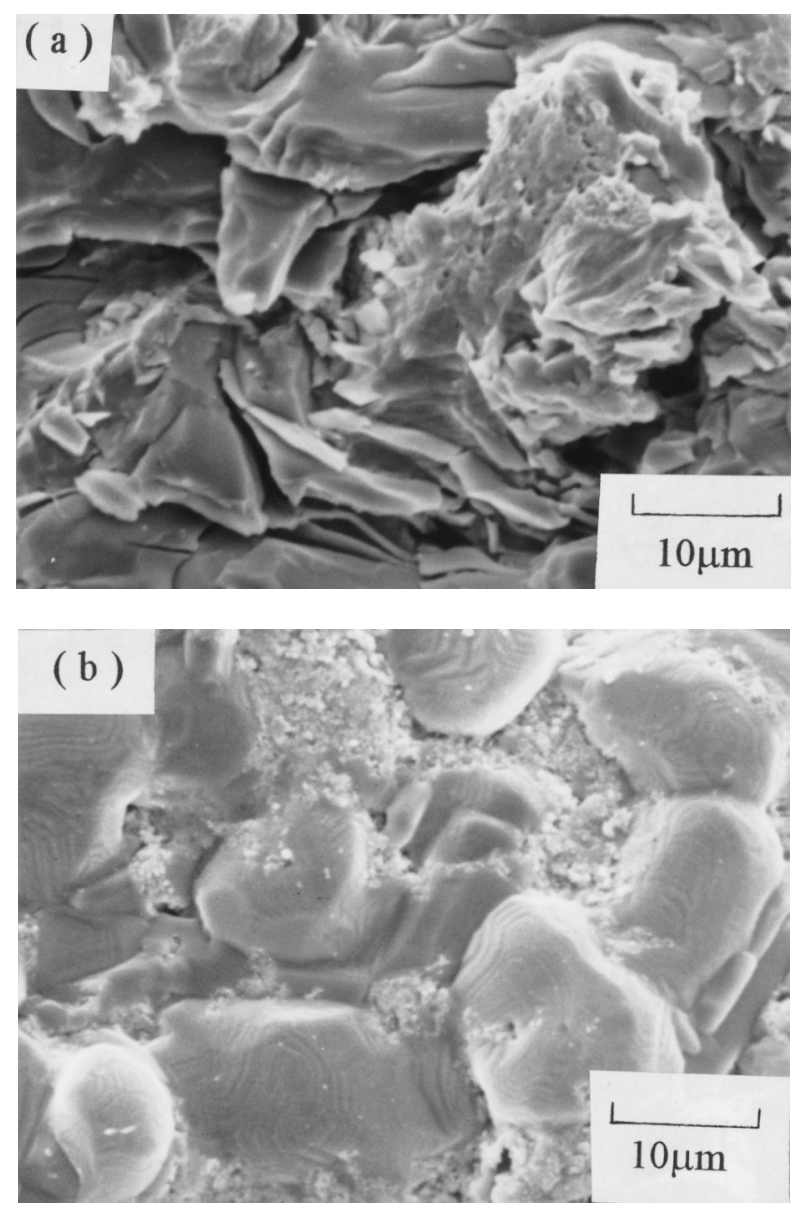

Fig. 15-Fractographs of brazements with Ni-Cr-P filler metal after brazing at $980{ }^{\circ} \mathrm{C}$ for 10 min under various pressures (overlapping length 3T): (a) $0 \mathrm{MPa}$ and (b) $7.0 \mathrm{MPa}$.

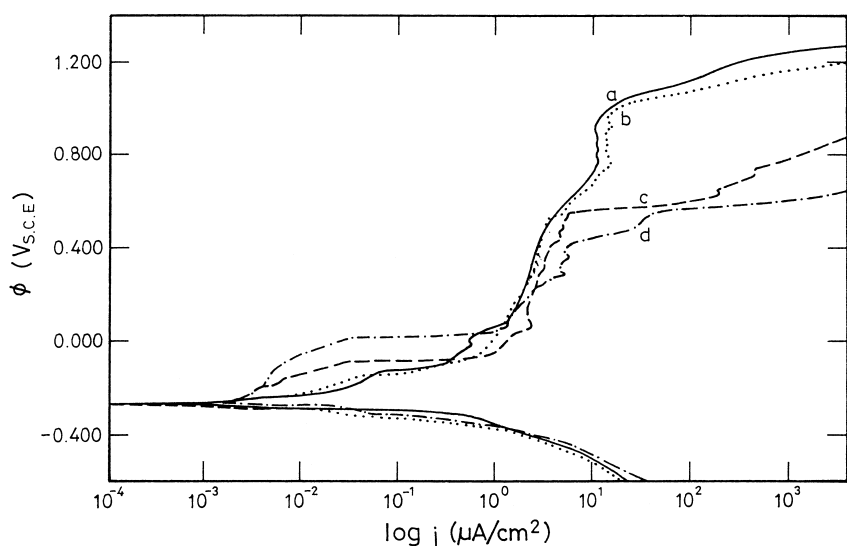

Fig. 16- Corrosion polarization curves of INCONEL 718SPF superalloy brazements in a $3.5 \mathrm{pct} \mathrm{NaCl}$ solution: $(a)$ as-received, $(b)$ base metal, $(c)$ Ni-Cr-P brazements, and (d) Ni-P brazements.

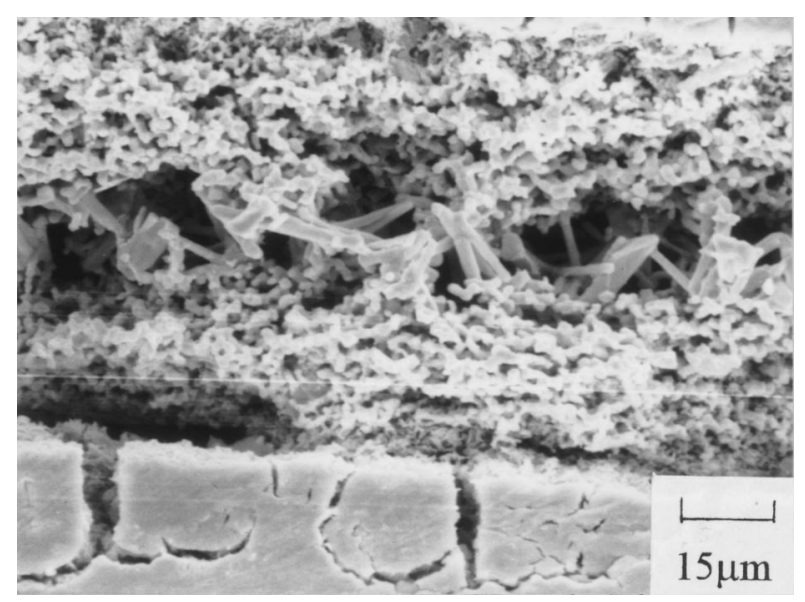

Fig. 17-Corrosion morphology of INCONEL 718SPF superalloy brazements with Ni-P filler metal after polarization test in a $3.5 \mathrm{pct} \mathrm{NaCl}$ solution.

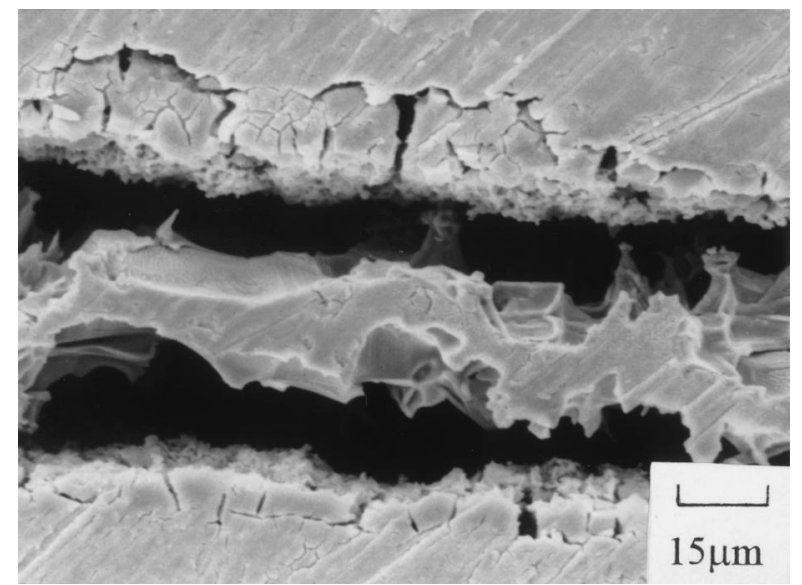

Fig. 18-Corrosion morphology of INCONEL 718SPF superalloy brazements with $\mathrm{Ni}-\mathrm{Cr}-\mathrm{P}$ filler metal after polarization test in a $3.5 \mathrm{pct}$ $\mathrm{NaCl}$ solution.

\section{REFERENCES}

1. D. Bose, A. Datta, A. Rabinkin, and N.J. De Cristofaro: Weld. Res. Suppl., 1986, vol. 65, pp. 23s-29s.

2. B. Grushko and B.Z. Weiss: Metall. Trans. A, 1984, vol. 15A, pp. 60920.

3. A. Rabinkin and S. Pounds: Weld. J., 1988, vol. 67, pp. 33-45.

4. R. Dammer: in Beitrag zur Bewertung Mechanischer Eigenschaften Hochtemperaturgelöteter Superlegierungen, Deutscher Verlag für Schweißtechnik (DVS), Düsseldorf, 1986, pp. 61-66.

5. G.D. Smith and H.L. Flower: Industrial Heat., 1995, Apr., pp. 47-49.

6. K.H. Holko and T.J. Moore: Weld. Res. Suppl., 1972, vol. 51, pp. $81 \mathrm{~s}-89 \mathrm{~s}$.

7. Binary Alloy Phase Diagrams, T.B. Massalski, ed., ASM, Metals Park, OH, 1986, vol. 2, pp. 1738-39.

8. Principles of Soldering and Brazing, 1st ed., G. Humpston and D.M. Jacobson, eds., ASM INTERNATIONAL, Materials Park, OH, 1993, pp. 111-44.

9. M.H. Slobada: Weld. Met. Fabr., 1961, vol. 7, pp. 291-96. 